\title{
Review Article \\ The Role of Matrix Metalloproteinase-9 in Atherosclerotic Plaque Instability
}

\author{
Tiewei Li $\mathbb{D},{ }^{1}$ Xiaojuan $\mathrm{Li}^{2},{ }^{2}$ Yichuan Feng, ${ }^{1}$ Geng Dong, ${ }^{1}$ Yuewu Wang $\mathbb{D},{ }^{3}$ \\ and Junmei Yang $\mathbb{D}^{1}$ \\ ${ }^{1}$ Zhengzhou Key Laboratory of Children's Infection and Immunity, Children's Hospital Affiliated to Zhengzhou University, \\ Henan Children's Hospital, Zhengzhou Children's Hospital, 33 Longhu Waihuan East Street, Jinshui District, \\ Zhengzhou 450000, China \\ ${ }^{2}$ Children's Hospital Affiliated to Zhengzhou University, Henan Children's Hospital, Zhengzhou Children's Hospital, 33 Longhu \\ Waihuan East Street, Jinshui District, Zhengzhou 450000, China \\ ${ }^{3}$ The Engineering Research Center for New Drug Screening, Inner Mongolia Medical University, Hohhot, China
}

Correspondence should be addressed to Tiewei Li; litieweind@163.com, Yuewu Wang; 20090029@immu.edu.cn, and Junmei Yang; yangjunmei7683@163.com

Received 13 June 2020; Revised 10 August 2020; Accepted 23 September 2020; Published 6 October 2020

Academic Editor: Kutty Selva Nandakumar

Copyright ( 2020 Tiewei Li et al. This is an open access article distributed under the Creative Commons Attribution License, which permits unrestricted use, distribution, and reproduction in any medium, provided the original work is properly cited.

\begin{abstract}
Matrix metalloproteinase-9 (MMP-9) belongs to the MMP family and has been widely investigated. Excessive MMP-9 expression can enhance extracellular matrix degradation and promote plaque instability. Studies have demonstrated that MMP-9 levels are higher in vulnerable plaques than in stable plaques. Additionally, several human studies have demonstrated that MMP-9 may be a predictor of atherosclerotic plaque instability and a risk factor for future adverse cardiovascular and cerebrovascular events. MMP-9 deficiency or blocking MMP-9 expression can inhibit plaque inflammation and prevent atherosclerotic plaque instability. All of these results suggest that MMP-9 may be a useful predictive biomarker for vulnerable atherosclerotic plaques, as well as a therapeutic target for preventing atherosclerotic plaque instability. In this review, we describe the structure, function, and regulation of MMP-9. We also discuss the role of MMP-9 in predicting and preventing atherosclerotic plaque instability.
\end{abstract}

\section{Introduction}

Vulnerable plaques are a leading cause of acute coronary syndrome and sudden death. Studies have shown that $75 \%$ of acute coronary syndrome cases are caused by plaque rupture $[1,2]$. According to the consensus document published in 2003 by Naghavi et al. [3], vulnerable plaques are defined as any types of plaques with a high likelihood of thrombotic complications and rapid progression and are characterized by a thin fibrous cap $(<65 \mu \mathrm{m})$, large lipid pool $(>40 \%$ of the plaque), infiltration of inflammatory cells (particularly macrophages), outward remodeling, neovascularization, and intraplaque hemorrhage $[4,5]$. Mature plaques mainly comprise endothelial cells (ECs), vascular smooth muscle cells (VSMC), macrophages, and a fibrous cap containing extracellular matrix (ECM) components [6]. Among these compo- nents, the ECM plays an especially important role in plaque stability [7].

Matrix metalloproteinases (MMPs) are members of the metzincin protease superfamily of zinc-endopeptidases. At present, the MMP family itself includes 28 members [8]. MMPs have a specific proteolytic activity against the ECM; their action can result in the thinning of the fibrous cap and plaque instability $[6,9]$. MMP-9, also known gelatinase $\mathrm{B}$, is a widely investigated member of the MMP family. Studies have shown that there is a strong relationship between MMP-9 and plaque instability [10-12]. Histopathological studies showed that MMP-9 was mostly distributed in the shoulder regions, necrotic core, and the fibrous cap of the atherosclerotic plaques, and that MMP-9 levels and activity were higher in unstable plaques than in stable plaques [13-16]. In addition, many studies have suggested that 
high MMP-9 levels can serve as a predictor of atherosclerotic plaque instability, and furthermore, that excessive MMP-9 expression may contribute to the plaque instability [17-19], indicating that MMP-9 may be a potential target for preventing atherosclerotic plaque instability. This review will explore the function of MMP-9 in vulnerable plaques and primarily discuss the predictive and preventive value of MMP-9 in atherosclerotic plaque instability.

\section{Molecular Architecture and MMP-9 Regulation}

2.1. MMP-9 Molecular Architecture. The majority of MMPs (with the except of matrilysins and MMP-26) have a similar structure, including a signal peptide, a propeptide, an active site, a $\mathrm{Zn}^{2+}$ binding domain, and a hemopexin domain [20, 21]. In addition, MMP-9 has an O-glycosylated domain and three fibronectin repeats (MMP-2 also has fibronectin repeats) $[22,23]$. These structural domains form an inactive $92 \mathrm{kDa}$ pro-MMP-9 or an active $82 \mathrm{kDa}$ MMP-9 [24]. MMP-9 also exists in a third form as a $65 \mathrm{kDa}$ protein that lacks the carboxyterminal hemopexin domain and amino terminal propeptide [25]. The catalytic domain of MMP-9 is composed of the active site and the zinc-binding sites and can be inhibited by propeptide. The propeptide region contains the "cysteine switch" consensus sequences PRCXXPD [26] and is degraded during enzyme activation. The native ECM is cleaved by collagenase MMP-1, MMP-3, or MMP13 into $1 / 4$ and $3 / 4$ fragments, which are subsequently degraded further by other MMPs, such as MMP-2, MMP-3, and MMP-9 [27].

The sequence of the MMPs hemopexin domain is similar to that of plasma hemopexin, but MMP-9 only has $25 \%-33 \%$ sequence similarity with other MMPs [28]. The hemopexin domain of pro-MMP-9 binds to the C-terminal domain of tissue inhibitors of metalloproteinases (TIMPs) forming a tight complex [29]. MMP-9 can also bind to surface receptors that interact with substrates and induce autoactivation [24]. A number of studies have shown that the O-glycosylated (OG) domain, a unique linker sequence located between the hemopexin domain and the active site, is essential for MMP-9 function [20, 22, 30]. A deficiency in the OG domain significantly attenuates MMP-9-mediated cell migration and decreases gelatinolytic activity [31]. The OG domain also enables the catalytic domain and the terminal hemopexin domain of MMP-9 to move flexibly, which is important for denatured collagens degradation [24, 32].

MMP-9 exists in a variety of forms, including monomers, oligomers, a truncated form, or in a complex with other molecules [24, 33], and the monomer is the dominant form in human tissue and blood. The MMP-9 monomer can also form oligomers through intermolecular cysteine bridges. Dufour et al. [28, 30] reported that MMP-9 multimers can bind to CD44, further promoting the migration of cancer cells via activation of EGFR and the MAPK signaling pathway. Moreover, pro-MMP-9 trimers have a higher affinity for TIMP-1 than the monomers [34]. MMP-9 can also form a complex with neutrophil gelatinase-associated lipocalin (NGAL). The NGAL/MMP-9 complex, mainly secreted by neutrophils, is more stable than MMP-9 and can prevent MMP-9 from being degraded [35]. In addition, Winberg et al. [36] reported that macrophages secrete pro-MMP-9 covalently linked to the core protein of chondroitin sulfate proteoglycans via one or more disulphide bridges.

\subsection{Regulation of MMP-9 Expression and Activity}

2.2.1. Regulation of MMP-9 Expression. The promoter region of the MMP-9 gene has many transcription factor binding sites, such as nuclear factor $\kappa \mathrm{B}(\mathrm{NF}-\kappa \mathrm{B})$, activator protein-1 (AP-1), and specificity protein 1 (Sp-1) [37]. These transcription factors can enhance the transcription activity of MMP-9. MMP-9 can be secreted by multiple cell types, including macrophages, SMCs, and ECs. Bansal et al. [38] reported that macrophages expressed MMP-9 after stimulation with phosphatidyl-myo-inositol dimannosides (PIM2) through PI3K and Notch1 signaling pathways. SMCs also exhibited augmented expression of MMP-9, increased MMP-9 enzymatic activity, and impaired function of collagen assembly upon cross-talk with macrophages in high glucose conditions [39]. In addition, Magid et al. [40] found that the expression of MMP-9 in ECs is flow-sensitive and is upregulated by oscillatory flow via c-Myc activation. All of these effects on the regulation of MMP-9 expression may contribute to the development and progression of atherosclerosis.

2.2.2. Activation of the MMP-9. Most MMPs are expressed and secreted as an inactive zymogens form, which is called pro-MMPs [41]. Activation of membrane-type MMPs (MTMMPs) involves removal of the prodomain by furins in the endosomal pathway, while other MMPs rely on the cysteine switch mechanism [32]. MMP propeptide holds a cysteine which interacts with the active site zinc ion and thereby keeps the enzyme inactive. The cysteine switch mechanism means that pro-MMP activation requires disruption of the interaction between the cysteine switch and the zinc-binding site in the catalytic domain, either by proteolytic removal of the propeptide or by chemical modification of the cysteine. As reviewed by Yabluchanskiy et al. [37], MMP-9 can be activated by multiple MMPs and proteolytic enzymes, such as MMP-2, MMP-3, MMP-13, MMP-17, MMP-26, and proteolytic enzymes such as urokinase-type plasminogen activator (uPA), plasmin, and tissue-type plasminogen activator. In addition, low $\mathrm{pH}$, sodium dodecyl sulfate (SDS), other denaturing agents, and heat treatment can also activate MMP-9 by cleaving its predomain [42].

2.2.3. Endogenous Inhibitors of MMPs. TIMPs are the main physiological inhibitors of MMPs in vivo. Of the four known TIMPs, TIMP-1 inhibits MMP-9 with high-affinity $[43,44]$. The C-terminal domain of TIMP-1 can bind with the hemopexin domain of pro-MMP-9 to form a tight complex, thus inhibiting MMP-9 activation, as well as TIMP-3 [29]. Several studies have shown that MMP-9 and TIMP-1 are coexpressed in many types of cells (except neutrophils that do not express TIMP-1) and are secreted as an MMP-9/TIMP-1 complex [30, 45]. However, Serifova et al. [46] found that homotrimeric MMP-9 could efficiently cleave the alpha-2macroglobulin $(\alpha 2 \mathrm{M})$, induce $\alpha 2 \mathrm{M}$ conformational changes 
$(\alpha 2 \mathrm{M} *)$, and form covalent complexes ( $\alpha 2 \mathrm{M} * / \mathrm{MMP}-9)$, and hence escape protease inhibition and internalization. Endogenous inhibitors and MMP-9 are in a dynamic balance under physiological conditions, but this balance will be disrupted under certain pathological conditions.

\section{MMP-9 and Atherosclerosis}

Acute coronary events, approximately $75 \%$ of which are caused by unstable plaque rupture, present a serious threat to human life $[1,2]$. The transition from stable to unstable plaques involves ECM remodeling, and altered MMP-9 activity accelerates unstable plaque development [47-49].

3.1. Role of MMP-9 in Atherosclerotic Plaque Instability. The presence of MMP-9 protein in human coronary atherosclerotic lesions was first reported by Brown et al. in 1997 [50]. Many subsequent studies have shown that MMP-9 is involved in the process of atherosclerosis development $[51,52]$. When under stress, ECs exhibited augmented MMP-9 expression and activity [40]. Increased MMP-9 expression and activity promote ECM degradation, which can enhance inflammatory cell infiltration. Histopathological studies showed that MMP-9 was mostly distributed in the shoulder regions, necrotic core, and the fibrous cap of carotid atherosclerotic plaques [53] that contained an abundance of inflammatory cells [54]. The inflammatory cells are the primary source of MMP-9 within the plaque [55]. Chen et al. [56] reported that macrophage-derived MMP-9 could promote the infiltration of monocyte/macrophages into the lesions but had no effect on the fatty streak size. Only overexpression of the autoactivating form of MMP-9 in macrophages can induce significant plaque disruption [57]. In addition, MMP-9 can also promote the migration of VSMCs. VSMC can further secrete vascular endothelial growth factor (VEGF), which plays an important role in neovascularization (a risk factor for plaque instability). Papalambros et al. [58] reported that MMP-9 and VEGF are expressed in parallel in neovascularized plaque lesions. MMP-9 may influence the stability of plaques indirectly via effects on neovascularization. Animal experiments have shown that plaque volume and length are significantly reduced in MMP-9-deficient mice. Carotid plaques in these mice accumulated less SMC, collagen, intraplaque foam cells, and macrophages [59]. MMP-9 deficiency also impairs compensatory vessel enlargement [47]. However, MMP-9 has a dual role in atherosclerosis, as reviewed by Newby et al. [55]. MMP-9 could facilitate the contact between SMCs and the interstitial matrix through degrading the ECM around VSMCs, resulting in a change from quiescent, contractile VSMCs to cells capable of migrating, proliferating, and subsequent intimal thickening. Lemaître et al. [60] reported that overexpression of pro-MMP-9 in macrophages did not induce plaque rupture but resulted in augmented collagen deposition, suggesting that MP-9 had a protective role in plaque in instability. Johnson et al. [61] further demonstrated that loss of MMP-9 significantly reduced SMC content, increased plaque area, and resulted in higher macrophage infiltration. The extent to which these two opposite effects on stability occur in vivo remains to be elucidated.

MMP-9 is also present in atherosclerotic lesions of coronary arteries and the aorta. Jiang et al. [62] found that MMP-9 expression was elevated in porcine coronary artery intima with unstable plaques. Morishige et al. [63] further reported that overexpression of MMP-9 in porcine coronary arteries after balloon injury promoted thrombus formation, and that MMP-9 deficiency reduced the aorta's atherosclerotic burden and suppressed macrophage infiltration, while loss of MMP-12 did not affect the lesion growth. This difference in effect may be due to the difference in substrates between MMPs; MMP-9 disrupts the basement membrane collagen, initiating the development of atherosclerosis, while MMP-12 mainly degrades the elastic laminae of atherosclerotic media without affecting plaque growth [64]. Loss of MMP-9 can also prevent aortic dilatation and the formation of abdominal aortic aneurysms (AAA) [65]. Silencing of MMP-9 can also reduce the C-reactive protein levels (CRP) in aortic atherosclerotic plaques indicating that MMP-9 deficiency may stabilize the plaques by inhibiting their inflammation [66]. Galis et al. [67] further found that targeted disruption of the MMP-9 gene can prevent SMC migration and limit the effects of pathological arterial remodeling in restenosis and atherosclerosis. More importantly, a clinical study reported that the expression of the MMP-9 gene and protein is more abundant in unstable plaques, and that transcription factors $\mathrm{AP}-1$ and $\mathrm{NF}-\kappa \mathrm{B}$ are more frequently detected in unstable plaques that have been shown to upregulate MMP-9 expression [11]. A synopsis of potential MMP-9-mediated mechanisms driving plaque instability has been visualized in Figure 1.

3.2. Predictive Value of MMP-9 in Atherosclerosis. At a diagnostic or prognostic level, circulating MMP-9 levels have been suggested to be a biomarker for predicting the stability of atherosclerotic plaques and the risk of future adverse cardiovascular and cerebrovascular events. Fukuda et al. [19] reported that the serum levels of MMP-9 were elevated in patients with ruptured plaques compared with the patients without ruptured plaques, and that MMP-9 was an independent predictor of plaque rupture. Elevated serum levels of MMP-9 also have a positive association with high total carotid artery plaque score, larger intima-media thickness (IMT) value, and plaque instability [68]. Olson et al. [69], however, did not find an association between plasma MMP-9 concentration and carotid plaques, but total and active MMP-9 concentration were associated with femoral artery plaques and IMT. These differences between studies may be due to the different types of samples evaluated in each study. Several studies have shown that MMP-9 levels are higher in serum than in plasma and found a stronger association between MMP-9 levels and neutrophils in serum than in plasma, possibly due to leucocyte activation during the clotting process $[69,70]$. MMP-9 levels also vary between patients with acute myocardial infarction (AMI) and unstable angina pectoris (UAP); serum MMP-9 levels are higher in patients with ST segment elevation myocardial infarction (STEMI) than in those with non-STEMI (NSTEMI) or 

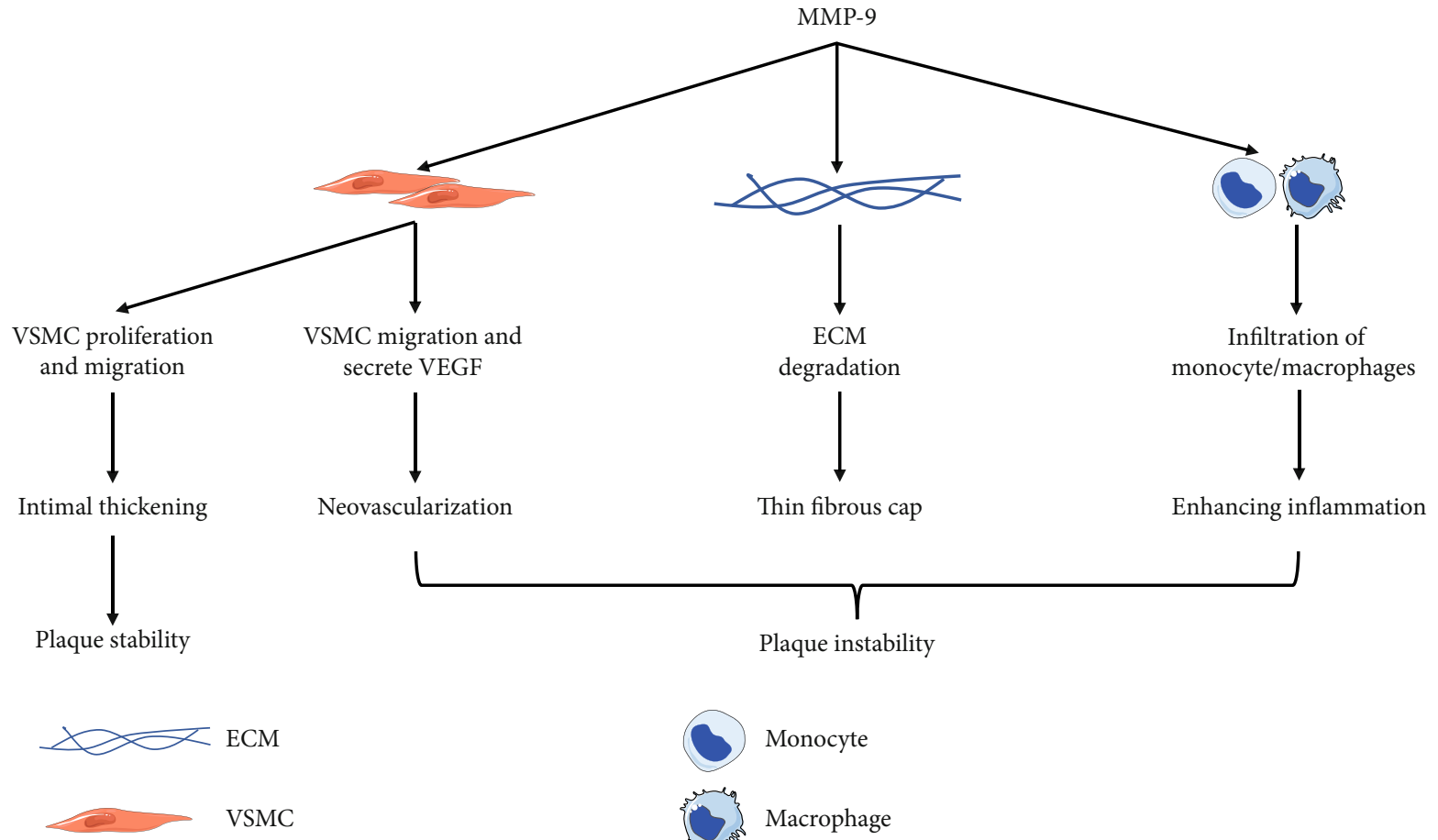

Monocyte

Macrophage

FIgURE 1: Emerging roles of MMP-9 in atherosclerosis, atherothrombosis, and vulnerable plaques. Abbreviations: MMP-9: matrix metalloproteinase-9; ECM: extracellular matrix; VSMC: vascular smooth muscle cell; VEGF: vascular endothelial growth factor.

UAP [71]. There is a higher frequency of plaque rupture, thin-cap fibro atheroma (TCFA), and red thrombi in patients with STEMI than in those with NSTEMI, suggesting that MMP-9 may be released from vulnerable plaques [72]. However, elevated levels of MMP-9 in plaque tissue may not result in a higher level of circulating MMP-9 in the blood [73]. In addition, active MMP- 9 was efficiently complexed to $\alpha 2 \mathrm{M}$ in human plasma, resulting in a shift of active MMP-9 into high molecular weight complexes, which could not be detected by standard analysis methods [46]. Therefore, the detrimental MMP-9 activity may persist due to the $\alpha 2 \mathrm{M} *$ /MMP-9 trimer complexes.

MMP-9 can be secreted by many types of inflammatory cells, including monocytes, macrophages, neutrophils, and foam cells [24]. Under normal physiological conditions, peripheral blood monocytes express low levels of MMP-9, but MMP-9 expression increases under pathological conditions when it is upregulated by many proinflammatory factors and the ECM [74-76]. Brunner et al. [77] reported that the monocytic MMP-9 mRNA expression is higher in patients with UAP/NSTEMI than in healthy individuals or patients with stable angina pectoris (SAP). Many studies have reported that MMP-9 levels are strongly associated with neutrophils, where MMP-9 is abundant in neutrophils [78, 79]. Compared with the de novo production of MMP-9 by macrophages, neutrophils have MMP-9 prestored in secretory granules for quick release under stimuli [80]. These findings suggest that MMP-9 may be secreted by inflammatory cells. In addition, plasma MMP-9 levels are significantly increased in infarct-related arteries than in the femoral artery and peripheral vein and are positively correlated with the volume of myocardial infarc- tion (MI) area, suggesting that MMP-9 may also be released from the infarcted myocardium [81-83].

The expression of MMP-9 also has temporal and spatial features. MMP-9 levels are significantly increased in patients with MI and return to baseline within one week [82]. Inokubo et al. [84] reported that the plasma MMP-9 levels are significantly increased in coronary circulation, but not in the aortic root. Circulating MMP-9 levels are further elevated after mechanical disruption of plaques by percutaneous coronary intervention [85]. These findings suggest that the elevation of MMP-9 in coronary circulation may be due to secretion by vulnerable plaques. Another study reported that the MMP-9 levels significantly increased more in early acute coronary syndrome (ACS) ( $\leq 4 \mathrm{~h}$ after oneset) than in late ACS ( $>4 \mathrm{~h}$ after oneset). In contrast, high-sensitivity tropo$\operatorname{nin} \mathrm{T}$ (hs-TnT) levels are lower in early ACS than in late ACS [71]. This study also reported that MMP-9 plasma levels increased earlier than levels of hs-TnT. MMP-9 is thus a better marker than hs-TnT for the diagnosis of early ACS, as it reflects plaque rupture or vulnerability [71].

Although many studies have shown that MMP-9 can serve as a biomarker of vulnerable plaques, its predictive value for adverse cardiovascular and cerebrovascular outcomes is controversial. Hamed et al. [86] reported that patients with ACS who have adverse cardiovascular events have a higher level of MMP-9. MMP-9 levels can also be used to predict ischemic stroke and cardiovascular death in patients with $>$ or $=50 \%$ carotid stenosis [87]. However, Jefferis et al. [88] pointed out that serum MMP-9 is not a strong predictor for MI and stroke in older men and women. The possible explanation for these inconsistent results may 
be that the two studies have different populations. In the general population, serum MMP-9 levels are associated with the incidence of coronary heart disease (CHD) [89], but the odds ratio decreased significantly to borderline after adjustment for conventional risk factors (especially smoking) [90]. In a study by Eldrup et al. [91], MMP-9 levels were not a valuable predictor for UAP, MI, or death in patients with stable coronary disease, while CRP levels could predict poor disease outcomes. The controversy over the predictive value of MMP-9 for adverse cardiovascular outcomes requires further evaluation in future studies. Eighteen studies of the association between circulating MMP-9 levels and atherosclerosis are summarized in Table 1.

3.3. MMP-9 Gene Polymorphisms in Atherosclerosis. The human MMP-9 gene is located on chromosome 20q12.213.1. A number of single nucleotide polymorphisms (SNPs) are present in the promoter, coding, and untranslated regions of the MMP-9 gene, the $1562 \mathrm{C}>\mathrm{T}$ polymorphism in the promoter and the 279 polymorphism (R279Q) in the coding region being of special interest. The $1562 \mathrm{C}>\mathrm{T}$ polymorphism in the MMP-9 gene results in a cytosine base replacing a thymine base at position -1562 [92]. The $\mathrm{C}$ allele has higher affinity for binding the transcriptional repressor protein than the T allele, resulting in enhanced MMP-9 promoter activity. The R279Q polymorphism of the MMP-9 gene refers to the replacement of amino acid arginine (R) with glutamine (Q) in the catalytic domain of MMP-9, enhancing its binding ability to substrates [93, 94]. Zhang et al. [95] reported that the $1562 \mathrm{C}>\mathrm{T}$ polymorphism of the MMP-9 gene affects MMP-9 gene transcription, resulting in high $(\mathrm{C} / \mathrm{T}, \mathrm{T} / \mathrm{T})$ or low $(\mathrm{C} / \mathrm{C})$ promoter activity. Further analysis showed that there is an association between the $1562 \mathrm{C}>\mathrm{T}$ polymorphism in the MMP-9 gene and CHD severity. In addition, Wu et al. [96] reported that the $1562 \mathrm{C}>\mathrm{T}$ polymorphism in the MMP-9 gene may be a predictor of susceptibility to ischemic stroke. Patients with the T/T genotype tended to have larger areas of complicated and calcified lesions than patients with the $\mathrm{C} / \mathrm{C}$ genotype, while the MMP-9 genotype did not have a significant association with the degree of coronary artery stenosis [97].

However, there are some differences between reports on the relationship between the $1562 \mathrm{C}>\mathrm{T}$ polymorphism in the MMP-9 gene and cardiovascular disease (CVD). Morgan et al. [98] found that there was an association between the $1562 \mathrm{C}>\mathrm{T}$ polymorphism of the MMP-9 gene and CVD in the Caucasian population, while the $1562 \mathrm{C}>\mathrm{T}$ polymorphism was only associated with the early-onset coronary artery disease (age $<55$ years) in the Iranian population [99]. In the Chinese Uighur population, the $1562 \mathrm{C}>\mathrm{T}$ polymorphism of the MMP-9 gene is also significantly associated with $\mathrm{MI}$, with a synergistic effect being seen among smokers [100, 101]. Additionally, $\mathrm{Wu}$ et al. [102] reported that the $1562 \mathrm{C}>\mathrm{T}$ polymorphism in the MMP-9 gene was associated with coronary artery disease (CAD) in the Chinese Han population. Some studies, however, have pointed out that there are no significant associations between the $1562 \mathrm{C}>\mathrm{T}$ polymorphism in the MMP-9 gene and CVD in patients from Korean [103], Turkey [104], the Caucasus [105, 106],
Germany [92], and Italy [107]. Several meta-analyses have been carried out to evaluate the association between the $1562 \mathrm{C}>\mathrm{T}$ polymorphism of the MMP-9 gene and CVD, with conflicting results. Zhang et al. [108], in a meta-analysis of 26 studies, suggested that the $1562 \mathrm{C}>\mathrm{T}$ polymorphism was not associated with CAD in the overall population. However, results from two smaller meta-analyses showed that patients with $\mathrm{T}$ alleles had a higher risk of MI than patients with the $\mathrm{C} / \mathrm{C}$ genotype and found a significant association between the $1562 \mathrm{C}>\mathrm{T}$ polymorphism and $\mathrm{CHD}$, but not in the Asian population $[109,110]$. Interestingly, studies have shown no association between the R279Q polymorphism in the MMP-9 gene and CAD [100, 101, 106], but the R279Q polymorphism and smoking had a synergistic effect and were significantly associated with the risk of MI in the Chinese Uighur population [100, 101]. Opstad et al. [106] have reported that the $\mathrm{R} 279 \mathrm{Q}$ polymorphism also had a significant association with hypertension. These contradictory results may be due to the differences in the types of patients, ethnicities, and countries in the studies analyzed. Further largescale studies are needed to verify these findings and provide personalization of medical services for patients based on their countries, ethnicities, MMP-9 gene polymorphisms, and comorbidity. Studies about the association between MMP-9 gene polymorphisms and atherosclerosis are described in Table 2.

\section{Pharmacotherapy Targeting MMP-9 in Atherosclerosis}

TIMPs, the endogenous inhibitors of MMPs, play an important role in inhibiting MMPs activity. To date, four TIMPs have been identified, all of which can inhibit MMPs, but with different affinities. TIMP-1 can inhibit most of the MMPs (MMP-1, MMP-3, and MMP-9 in particular). TIMP-2 binds with good affinity to MMP-2. TIMP-3 is a powerful inhibitor of MMPs that are present in the ECM. TIMP-4 exhibits tissue-specific expression and is especially expressed in the heart [44, 111]. De Vries et al. [112] reported that TIMP-1 overexpression significantly attenuated plaque progression and increased the stability of vulnerable plaques in murine vein grafts. Compared with TIMP-1, two studies found that TIMP-2 played a greater protective role than TIMP-1 in preventing atherosclerotic plaque development.

In addition to TIMPs, synthetic inhibitors against MMPs have also been shown to be effective, and of these, doxycycline has been approved by the American Food and Drug Administration for clinical practice $[113,114]$. Doxycycline inhibits the expression and activity of MMP-9 [115, 116], and doxycycline treatment can significantly inhibit atherosclerosis development [117]. Doxycycline can also reduce the neointimal thickness and has a protective effect on left ventricular dilation [118]. However, a human study demonstrated that administration of doxycycline had no effect on MMP-9 expression in carotid plaques and plaque rupture [119]. Brown et al. [120] further demonstrated that although doxycycline induced a 50\% reduction in plasma pro-MMP-9 activity and exerted potentially beneficial effects on 


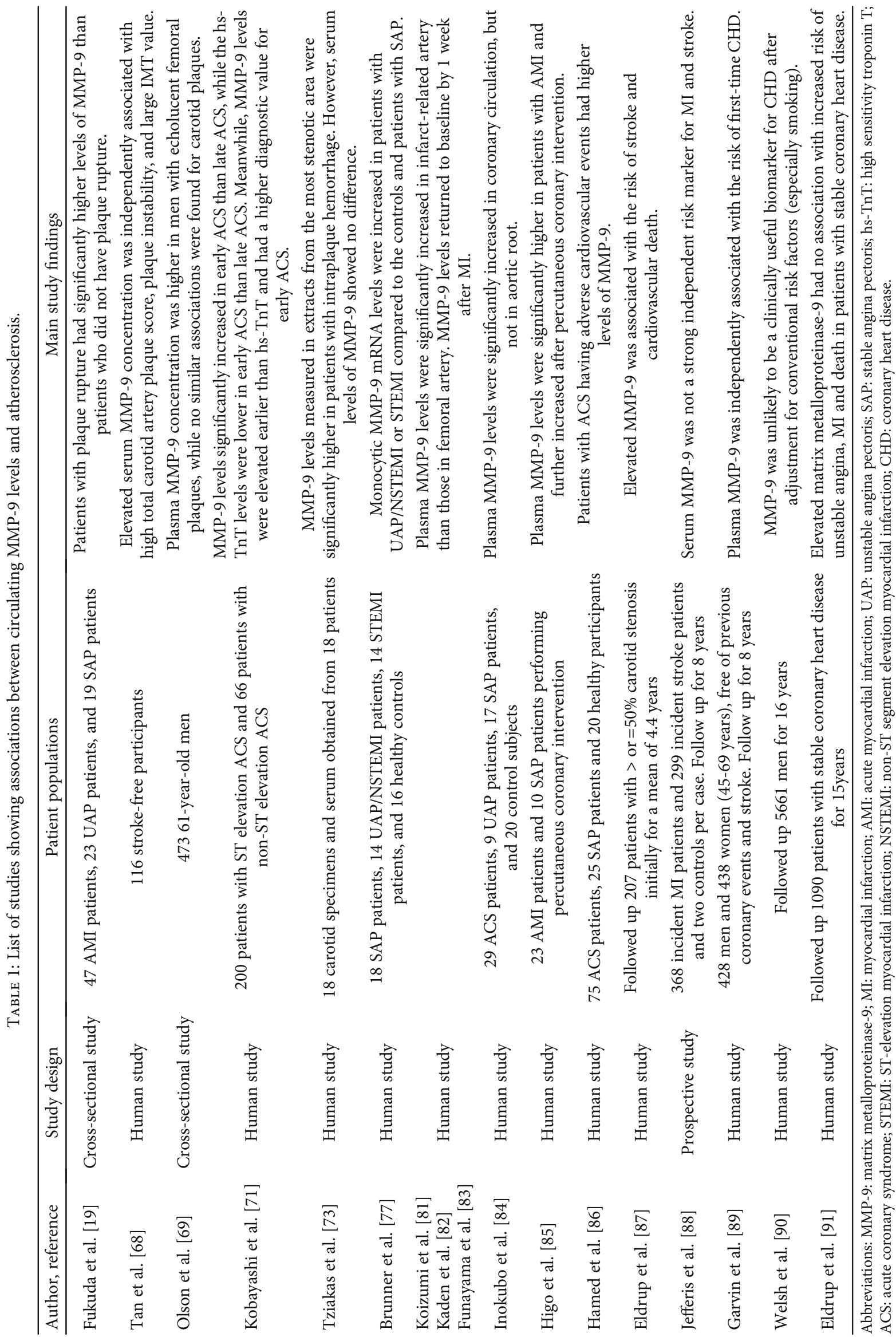




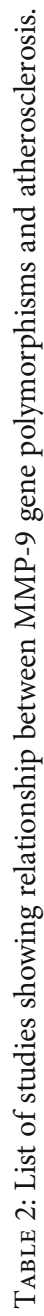

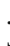

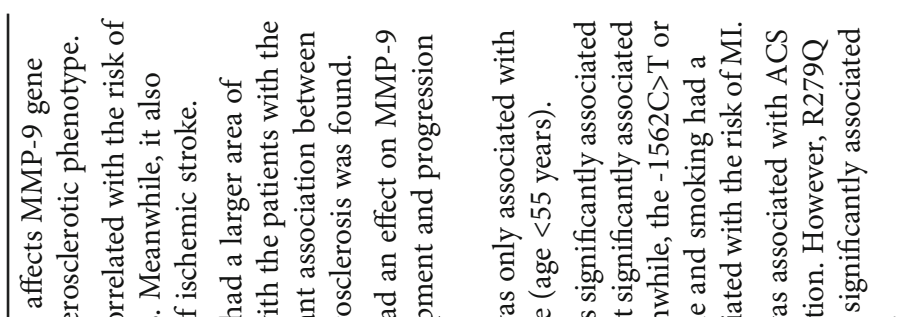

.0

要

胥

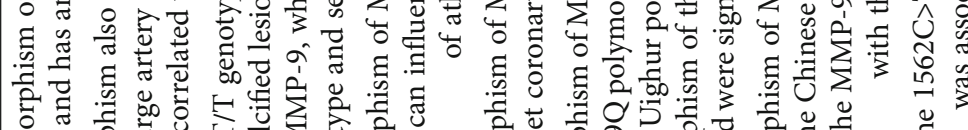

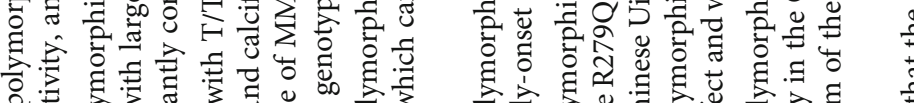

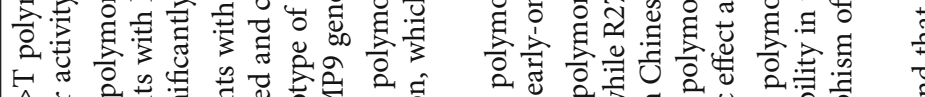

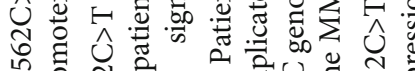

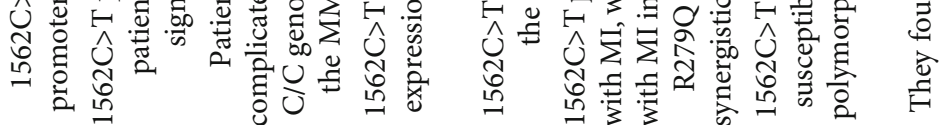

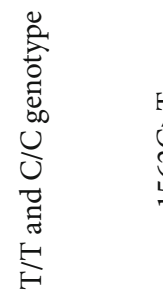

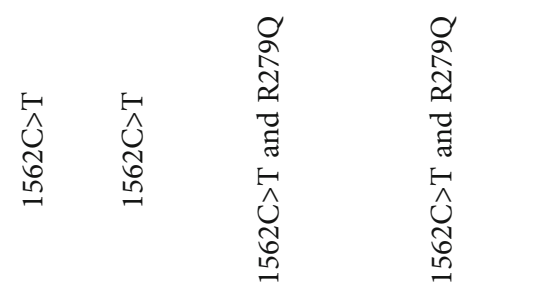

$F=\quad z$

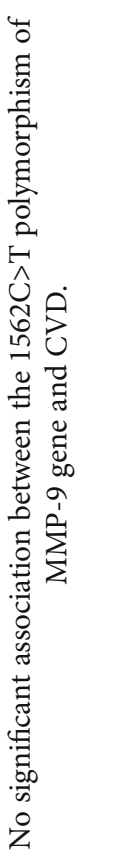

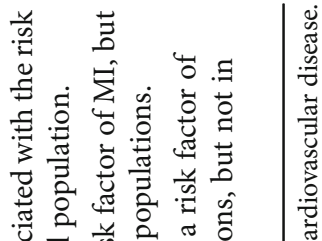

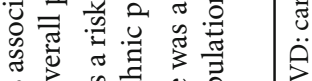

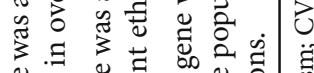

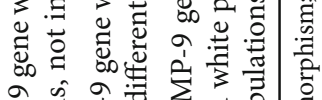

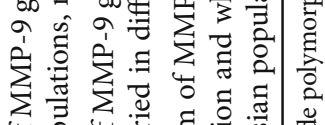

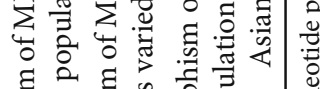

हี है है

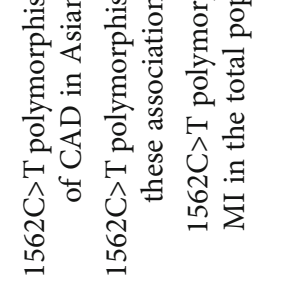

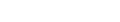

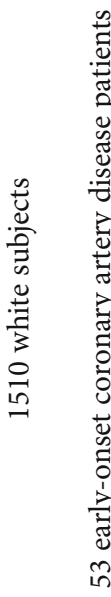

華

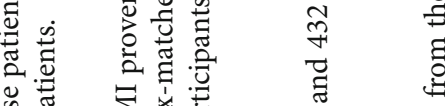

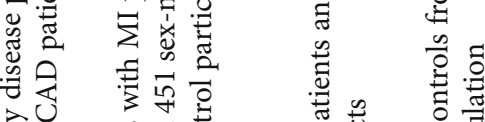

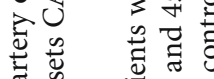

政

密.

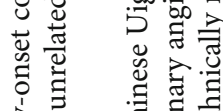

ฝั

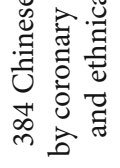

总

范 $\frac{\mathrm{m}}{3}$

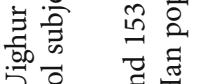

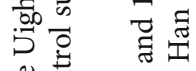

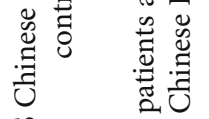

के

岂

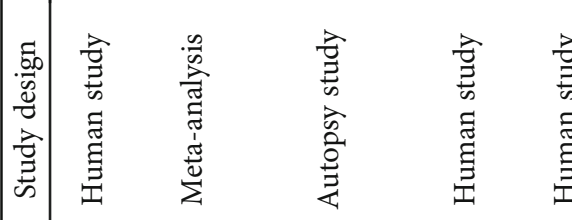

昰

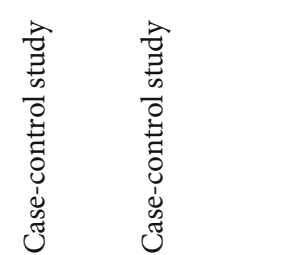

客

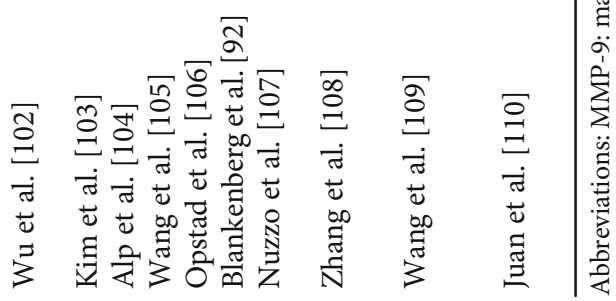


inflammation, it had no effect on the composite endpoint of sudden death, fatal MI, nonfatal MI, or troponin-positive UAP.

In addition, ONO-4817 is an ora MMP inhibitor that shows a broad spectrum of inhibitory activity. In an animal study, ONO-4817 treatment significantly inhibited MMP-9 activity within one day after MI oneset and attenuated the left-ventricular (LV) dilatation, as well as the development of cardiac dysfunction [121]. In addition, treatment with the MMP inhibitor PD166793 could also significantly reduce the infarct area and LV dilatation two weeks after MI [122]. However, MMP inhibitor PG-116800 failed to demonstrate that it could prevent LV remodeling and reduce the incidence of adverse cardiovascular events in the Prevention of Myocardial Infarction Early Remodeling (PREMIER) trial [123]. In addition, Johnson et al. [124] reported that broad-spectrum MMP inhibitor RS-130830 did not have a beneficial effect on atherosclerosis in the apolipoprotein E knockout mouse model.

Many studies have shown that common cardiovascular agents can also inhibit the expression or activity of MMP-9. Statins, widely applied in the clinical setting for hyperlipemia treatment, can inhibit the atherosclerosis development, stabilize the vulnerable plaques, and further reduce the adverse cardiovascular events $[125,126]$. Statins have also been shown to could restore the EC function, inhibit proliferation and migration of VSMCs, and attenuate inflammatory response [127]. Luan et al. [128] reported that statins could inhibit the MMP-9 secretion from rabbit SMCs and foam cells in a dose-dependent manner and had no effect on the production of TIMP-1, thereby disrupting the balance between MMP-9 and TIMP-1. Rival et al. [129] further demonstrated that MMP-9 secretion was inhibited by fluvastatin via the mevalonate starvation mechanism. In addition, a clinical study showed that the levels of MMP-9 significantly decreased in patients receiving statins [130]. Takai et al. [131] reported that lisinopril therapy, but not candesartan cilexetil, significantly inhibited both the activity of angiotensin-converting enzyme and MMP-9. Patients given imidapril had a lower MMP-9 activity than those given lisinopril, indicating that different hypertension drugs had different inhibitory effects on MMP-9 activity [132]. In addition, insulin treatment can also effectively reduce the diabetes-increased intimal lesion size and MMP-9 expression but has no effect on TIMP-1 expression and macrophage content of atherosclerotic plaques [133]. Several studies have also shown that the antidiabetic PPAR-activator rosiglitazone significantly reduces serum MMP-9 levels in type 2 diabetes mellitus patients [134]. A number of other compounds, such as estradiol [135, 136], lycopene [137], polyphenols [138], panax notoginsenosides (TPNS) [139], and tanshinone IIA [140] can also affect MMP-9 levels and activity.

\section{Conclusions}

Vulnerable plaques remain a high risk factor for cardiovascular and cerebrovascular diseases, as their rupture can cause acute coronary syndrome, stroke, and sudden death. Vulnerable plaques are characterized as those having a thin fibrous cap, a large lipid pool, and infiltration of inflammatory cells. Inflammatory cells can release large amounts of MMP-9 into plaque tissue, which can then degrade the ECM, resulting in a thin fibrous cap and plaque instability. Numerous studies have demonstrated that MMP-9 levels are higher in vulnerable plaques than in stable plaques, and high circulating levels of MMP-9 are closely related to adverse cardiovascular and cerebrovascular events [48, 53, 62, 141-143]. Depletion of the MMP-9 gene or inhibition of MMP-9 expression or activity can significantly prevent plaque instability. All of these results suggest that MMP-9 can be a predictor of atherosclerotic plaque instability, and that targeting MMP-9 can prevent atherosclerotic plaque instability. However, we need to consider the effect of some factors on the relationship between MMP-9 and plaque instability, such as countries, ethnicities, MMP-9 gene polymorphisms, and other underlying diseases. Further large-scale studies and meta-analyses are needed to evaluate the synergistic effects and provide personalization of medical services for people based on their countries, ethnicities, MMP-9 gene polymorphisms, and comorbidities. Although there have been some clinical studies on the clinical application of MMP-9 inhibitors, the study populations have been relatively small. In addition, specific inhibitors of MMP-9 are still lacking. Further studies should continue to develop specific MMP-9 inhibitors and evaluate their role in preventing plaque instability.

\section{Conflicts of Interest}

The authors declare that they have no conflict of interest.

\section{Authors' Contributions}

Tiewei Li and Xiaojuan Li have contributed equally to this work and should be considered co-first authors.

\section{Acknowledgments}

This work was supported by the Key Research, Development and Promotion Projects of Henan Province (202102310132) and Medical Science and Technology Project of Henan Province (2018020698). We also thank LetPub (http://www letpub.com) for its linguistic assistance during the preparation of this manuscript.

\section{References}

[1] P. Maurovich-Horvat, M. Ferencik, S. Voros, B. Merkely, and U. Hoffmann, "Comprehensive plaque assessment by coronary ct angiography," Nature Reviews. Cardiology, vol. 11, no. 7, pp. 390-402, 2014.

[2] A. W. Leber, F. von Ziegler, A. Becker et al., "Characteristics of coronary plaques before angiographic progression determined by multi-slice ct," The International Journal of Cardiovascular Imaging, vol. 24, no. 4, pp. 423-428, 2008.

[3] M. Naghavi, P. Libby, E. Falk et al., "From vulnerable plaque to vulnerable patient: a call for new definitions and risk assessment strategies: Part i," Circulation, vol. 108, no. 14, pp. 1664-1672, 2003. 
[4] W. E. Hellings, W. Peeters, F. L. Moll, and G. Pasterkamp, "From vulnerable plaque to vulnerable patient: the search for biomarkers of plaque destabilization," Trends in cardiovascular medicine., vol. 17, no. 5, pp. 162-171, 2007.

[5] K. Y. Lee and K. Chang, "Understanding vulnerable plaques: current status and future directions," Korean Circulation Journal, vol. 49, no. 12, pp. 1115-1122, 2019.

[6] K. Sakakura, M. Nakano, F. Otsuka, E. Ladich, F. D. Kolodgie, and R. Virmani, "Pathophysiology of atherosclerosis plaque progression," Heart, Lung \& Circulation, vol. 22, no. 6, pp. 399-411, 2013.

[7] S. Holm Nielsen, L. Jonasson, K. Kalogeropoulos et al., "Exploring the role of extracellular matrix proteins to develop biomarkers of plaque vulnerability and outcome," Journal of Internal Medicine, vol. 287, no. 5, pp. 493-513, 2020.

[8] S. A. Illman, J. Lohi, and J. Keski-Oja, "Epilysin (mmp-28)structure, expression and potential functions," Experimental Dermatology, vol. 17, no. 11, pp. 897-907, 2008.

[9] E. Falk, M. Nakano, J. F. Bentzon, A. V. Finn, and R. Virmani, "Update on acute coronary syndromes: the pathologists' view," European Heart Journal, vol. 34, no. 10, pp. 719-728, 2013.

[10] J. P. Park, B. K. Lee, J. M. Shim et al., "Relationship between multiple plasma biomarkers and vulnerable plaque determined by virtual histology intravascular ultrasound," Circulation Journal, vol. 74, no. 2, pp. 332-336, 2010.

[11] F. Chen, P. Eriksson, G. K. Hansson et al., "Expression of matrix metalloproteinase 9 and its regulators in the unstable coronary atherosclerotic plaque," International Journal of Molecular Medicine, vol. 15, no. 1, pp. 57-65, 2005.

[12] X. Q. Liu, Y. Mao, B. Wang et al., "Specific matrix metalloproteinases play different roles in intraplaque angiogenesis and plaque instability in rabbits," PLoS One, vol. 9, no. 9, 2014.

[13] Z. S. Galis, G. K. Sukhova, M. W. Lark, and P. Libby, "Increased expression of matrix metalloproteinases and matrix degrading activity in vulnerable regions of human atherosclerotic plaques," The Journal of Clinical Investigation, vol. 94, no. 6, pp. 2493-2503, 1994.

[14] C. Gu, F. Wang, Z. Zhao, H. Wang, X. Cong, and X. Chen, "Lysophosphatidic acid is associated with atherosclerotic plaque instability by regulating $\mathrm{nf}-\kappa \mathrm{b}$ dependent matrix metalloproteinase-9 expression via lpa(2) in macrophages," Frontiers in Physiology, vol. 8, p. 266, 2017.

[15] A. M. Volkov, I. S. Murashov, Y. V. Polonskaya et al., "changes of content of matrix metalloproteinases and their tissue expression in various types of atherosclerotic plaques," Kardiologiia, vol. 17, no. 10, pp. 12-18, 2018.

[16] I. M. Loftus, A. R. Naylor, S. Goodall et al., "Increased matrix metalloproteinase- 9 activity in unstable carotid plaques. A potential role in acute plaque disruption," Stroke, vol. 31, no. 1, pp. 40-47, 2000.

[17] X. B. Jiang, J. S. Wang, D. H. Liu, W. S. Yuan, and Z. S. Shi, "Overexpression of matrix metalloproteinase- 9 is correlated with carotid intraplaque hemorrhage in a swine model," Journal of NeuroInterventional Surgery, vol. 5, no. 5, pp. 473-477, 2013.

[18] R. de Nooijer, C. J. N. Verkleij, J. H. von der Thüsen et al., "Lesional overexpression of matrix metalloproteinase-9 promotes intraplaque hemorrhage in advanced lesions but not at earlier stages of atherogenesis," Arteriosclerosis, Thrombosis, and Vascular Biology, vol. 26, no. 2, pp. 340-346, 2006.
[19] D. Fukuda, K. Shimada, A. Tanaka et al., "Comparison of levels of serum matrix metalloproteinase- 9 in patients with acute myocardial infarction versus unstable angina pectoris versus stable angina pectoris," The American Journal of Cardiology, vol. 97, no. 2, pp. 175-180, 2006.

[20] R. Swetha, C. Gayen, D. Kumar, T. D. Singh, G. Modi, and S. K. Singh, "Biomolecular basis of matrix metallo proteinase-9 activity," Future Medicinal Chemistry, vol. 10, no. 9, pp. 1093-1112, 2018.

[21] N. Cui, M. Hu, and R. A. Khalil, "Biochemical and biological attributes of matrix metalloproteinases," Progress in Molecular Biology and Translational Science, vol. 147, pp. 1-73, 2017.

[22] P. E. Van den Steen, I. Van Aelst, V. Hvidberg et al., "The hemopexin and o-glycosylated domains tune gelatinase b/mmp-9 bioavailability via inhibition and binding to cargo receptors," The Journal of Biological Chemistry, vol. 281, no. 27, pp. 18626-18637, 2006.

[23] P. A. Elkins, Y. S. Ho, W. W. Smith et al., "Structure of the c-terminally truncated human prommp9, a gelatinbinding matrix metalloproteinase," Acta Crystallographica. Section D, Biological Crystallography, vol. 58, no. 7, pp. 1182-1192, 2002.

[24] J. Vandooren, P. E. Van den Steen, and G. Opdenakker, "Biochemistry and molecular biology of gelatinase b or matrix metalloproteinase-9 (mmp-9): the next decade," Critical Reviews in Biochemistry and Molecular Biology, vol. 48, no. 3, pp. 222-272, 2012.

[25] Y. Okada, Y. Gonoji, K. Naka et al., "Matrix metalloproteinase 9 (92-kda gelatinase/type iv collagenase) from ht 1080 human fibrosarcoma cells. Purification and activation of the precursor and enzymic properties," The Journal of Biological Chemistry, vol. 267, no. 30, pp. 21712-21719, 1992.

[26] P. E. Van den Steen, B. Dubois, I. Nelissen, P. M. Rudd, R. A. Dwek, and G. Opdenakker, "Biochemistry and molecular biology of gelatinase $\mathrm{b}$ or matrix metalloproteinase-9 (mmp-9)," Critical Reviews in Biochemistry and Molecular Biology, vol. 37, no. 6, pp. 375-536, 2002.

[27] S. Lenglet, F. Mach, and F. Montecucco, "Role of matrix metalloproteinase-8 in atherosclerosis," Mediators of Inflammation, vol. 2013, Article ID 659282, 6 pages, 2013.

[28] A. Dufour, N. S. Sampson, J. Li et al., "Small-molecule anticancer compounds selectively target the hemopexin domain of matrix metalloproteinase-9," Cancer Research, vol. 71, no. 14, pp. 4977-4988, 2011.

[29] H. Nagase, R. Visse, and G. Murphy, "Structure and function of matrix metalloproteinases and timps," Cardiovascular Research, vol. 69, no. 3, pp. 562-573, 2006.

[30] A. Dufour, N. S. Sampson, S. Zucker, and J. Cao, "Role of the hemopexin domain of matrix metalloproteinases in cell migration," Journal of Cellular Physiology, vol. 217, no. 3, pp. 643-651, 2008.

[31] J. Vandooren, N. Geurts, E. Martens et al., "Gelatin degradation assay reveals mmp-9 inhibitors and function of o-glycosylated domain," World Journal of Biological Chemistry, vol. 2, no. 1, pp. 14-24, 2011.

[32] G. Rosenblum, P. E. van den Steen, S. R. Cohen et al., "Direct visualization of protease action on collagen triple helical structure," PLoS One, vol. 5, no. 6, 2010.

[33] S. Hatipoglu, E. Sevketoglu, A. Gedikbasi et al., "Urinary mmp-9/ngal complex in children with acute cystitis," Pediatric Nephrology, vol. 26, no. 8, pp. 1263-1268, 2011. 
[34] J. Vandooren, B. Born, I. Solomonov et al., "Circular trimers of gelatinase b/matrix metalloproteinase- 9 constitute a distinct population of functional enzyme molecules differentially regulated by tissue inhibitor of metalloproteinases1," The Biochemical Journal, vol. 465, no. 2, pp. 259-270, 2015.

[35] L. Yan, N. Borregaard, L. Kjeldsen, and M. A. Moses, "The high molecular weight urinary matrix metalloproteinase (mmp) activity is a complex of gelatinase $\mathrm{b} / \mathrm{mmp}-9$ and neutrophil gelatinase-associated lipocalin (ngal). Modulation of mmp-9 activity by ngal," The Journal of Biological Chemistry, vol. 276, no. 40, pp. 37258-37265, 2001.

[36] J. O. Winberg, S. O. Kolset, E. Berg, and L. Uhlin-Hansen, "Macrophages secrete matrix metalloproteinase 9 covalently linked to the core protein of chondroitin sulphate proteoglycans," Journal of Molecular Biology, vol. 304, no. 4, pp. 669680, 2000.

[37] A. Yabluchanskiy, Y. Ma, R. P. Iyer, M. E. Hall, and M. L. Lindsey, "Matrix metalloproteinase-9: many shades of function in cardiovascular disease," Physiology, vol. 28, no. 6, pp. 391-403, 2013.

[38] K. Bansal, N. Kapoor, Y. Narayana, G. Puzo, M. Gilleron, and K. N. Balaji, "Pim2 induced cox-2 and mmp-9 expression in macrophages requires pi3k and notch1 signaling," PLoS One, vol. 4, no. 3, p. e4911, 2009.

[39] R. D. Macarie, M. Vadana, L. Ciortan et al., "The expression of mmp-1 and mmp-9 is up-regulated by smooth muscle cells after their cross-talk with macrophages in high glucose conditions," Journal of cellular and molecular medicine, vol. 22, no. 9, pp. 4366-4376, 2018.

[40] R. Magid, T. J. Murphy, and Z. S. Galis, "Expression of matrix metalloproteinase-9 in endothelial cells is differentially regulated by shear stress," Journal of Biological Chemistry, vol. 278, no. 35, pp. 32994-32999, 2003.

[41] Q. Chen, M. Jin, F. Yang, J. Zhu, Q. Xiao, and L. Zhang, "Matrix metalloproteinases: inflammatory regulators of cell behaviors in vascular formation and remodeling," Mediators of Inflammation, vol. 2013, Article ID 928315, 14 pages, 2013.

[42] E. B. Springman, E. L. Angleton, H. Birkedal-Hansen, and H. E. van Wart, "Multiple modes of activation of latent human fibroblast collagenase: evidence for the role of a cys73 active-site zinc complex in latency and a "cysteine switch" mechanism for activation," Proceedings of the National Academy of Sciences of the United States of America, vol. 87, no. 1, pp. 364-368, 1990.

[43] A. Papazafiropoulou and N. Tentolouris, "Matrix metalloproteinases and cardiovascular diseases," Hippokratia, vol. 13, no. 2, pp. 76-82, 2009.

[44] V. Arpino, M. Brock, and S. E. Gill, "The role of timps in regulation of extracellular matrix proteolysis," Matrix Biology, vol. 44, pp. 247-254, 2015.

[45] V. C. Ardi, T. A. Kupriyanova, E. I. Deryugina, and J. P. Quigley, "Human neutrophils uniquely release timp-free mmp-9 to provide a potent catalytic stimulator of angiogenesis," Proceedings of the National Academy of Sciences of the United States of America, vol. 104, no. 51, pp. 20262-20267, 2007.

[46] X. Serifova, E. Ugarte-Berzal, G. Opdenakker, and J. Vandooren, "Homotrimeric mmp-9 is an active hitchhiker on alpha-2-macroglobulin partially escaping protease inhibition and internalization through lrp-1," Cellular and Molecular Life Sciences, vol. 77, no. 15, pp. 3013-3026, 2020.
[47] S. M. Lessner, D. E. Martinson, and Z. S. Galis, “Compensatory vascular remodeling during atherosclerotic lesion growth depends on matrix metalloproteinase-9 activity," Arteriosclerosis, Thrombosis, and Vascular Biology, vol. 24, no. 11, pp. 2123-2129, 2004.

[48] R. Seifert, M. T. Kuhlmann, S. Eligehausen, F. Kiefer, S. Hermann, and M. Schäfers, "Molecular imaging of $\mathrm{mmp}$ activity discriminates unstable from stable plaque phenotypes in shear-stress induced murine atherosclerosis," PLoS One, vol. 13, no. 10, 2018.

[49] M. Dobaczewski, Y. Xia, M. Bujak, C. Gonzalez-Quesada, and N. G. Frangogiannis, "Ccr5 signaling suppresses inflammation and reduces adverse remodeling of the infarcted heart, mediating recruitment of regulatory t cells," The American journal of pathology, vol. 176, no. 5, pp. 2177-2187, 2010.

[50] D. L. Brown, M. S. Hibbs, M. Kearney, and J. M. Isner, "Differential expression of $92-k d a$ gelatinase in primary atherosclerotic versus restenotic coronary lesions," The American Journal of Cardiology, vol. 79, no. 7, pp. 878-882, 1997.

[51] J. L. Johnson, "Metalloproteinases in atherosclerosis," European Journal of Pharmacology, vol. 816, pp. 93-106, 2017.

[52] X. Wang and R. A. Khalil, "Matrix metalloproteinases, vascular remodeling, and vascular disease," Advances in Pharmacology, vol. 81, pp. 241-330, 2018.

[53] X. B. Jiang, W. S. Yuan, J. S. Wang, Z. Liu, D. H. Liu, and Z. S. Shi, "Matrix metalloproteinase-9 expression in carotid atherosclerotic plaque and contrast-enhanced mri in a swine model," Journal of NeuroInterventional Surgery, vol. 6, no. 1, pp. 24-28, 2014.

[54] H. Mangge and G. Almer, "Immune-mediated inflammation in vulnerable atherosclerotic plaques," Molecules, vol. 24, no. 17, p. 3072, 2019.

[55] A. C. Newby, "Dual role of matrix metalloproteinases (matrixins) in intimal thickening and atherosclerotic plaque rupture," Physiological Reviews, vol. 85, no. 1, pp. 1-31, 2005.

[56] Y. Chen, A. B. Waqar, K. Nishijima et al., "Macrophagederived mmp-9 enhances the progression of atherosclerotic lesions and vascular calcification in transgenic rabbits," Journal of Cellular and Molecular Medicine, vol. 24, no. 7, pp. 4261-4274, 2020.

[57] P. J. Gough, I. G. Gomez, P. T. Wille, and E. W. Raines, "Macrophage expression of active mmp-9 induces acute plaque disruption in apoe-deficient mice," The Journal of Clinical Investigation, vol. 116, no. 1, pp. 59-69, 2006.

[58] E. Papalambros, F. Sigala, S. Georgopoulos et al., "Vascular endothelial growth factor and matrix metalloproteinase 9 expression in human carotid atherosclerotic plaques: relationship with plaque destabilization via neovascularization," Cerebrovascular Diseases, vol. 18, no. 2, pp. 160165, 2004.

[59] E. T. Choi, E. T. Collins, L. A. Marine et al., "Matrix metalloproteinase- 9 modulation by resident arterial cells is responsible for injury-induced accelerated atherosclerotic plaque development in apolipoprotein e-deficient mice," Arteriosclerosis, Thrombosis, and Vascular Biology, vol. 25, no. 5, pp. 1020-1025, 2005.

[60] V. Lemaître, H. E. Kim, M. Forney-Prescott, Y. Okada, and J. D'Armiento, “Transgenic expression of matrix metalloproteinase-9 modulates collagen deposition in a mouse model of atherosclerosis," Atherosclerosis, vol. 205, no. 1, pp. 107-112, 2009. 
[61] J. L. Johnson, S. J. George, A. C. Newby, and C. L. Jackson, "Divergent effects of matrix metalloproteinases 3, 7, 9, and 12 on atherosclerotic plaque stability in mouse brachiocephalic arteries," Proceedings of the National Academy of Sciences of the United States of America, vol. 102, no. 43, pp. 1557515580, 2005.

[62] X. Jiang, H. S. Zeng, Y. Guo, Z. B. Zhou, B. S. Tang, and F. K. $\mathrm{Li}$, "The expression of matrix metalloproteinases-9, transforming growth factor-betal and transforming growth factor-beta receptor i in human atherosclerotic plaque and their relationship with plaque stability," Chinese Medical Journal, vol. 117, no. 12, pp. 1825-1829, 2004.

[63] K. Morishige, H. Shimokawa, Y. Matsumoto et al., "Overexpression of matrix metalloproteinase- 9 promotes intravascular thrombus formation in porcine coronary arteries in vivo," Cardiovascular Research, vol. 57, no. 2, pp. 572-585, 2003.

[64] A. Luttun, E. Lutgens, A. Manderveld et al., "Loss of matrix metalloproteinase- 9 or matrix metalloproteinase- 12 protects apolipoprotein e-deficient mice against atherosclerotic media destruction but differentially affects plaque growth," Circulation, vol. 109, no. 11, pp. 1408-1414, 2004.

[65] R. Pyo, J. K. Lee, J. M. Shipley et al., “Targeted gene disruption of matrix metalloproteinase-9 (gelatinase b) suppresses development of experimental abdominal aortic aneurysms," The Journal of Clinical Investigation, vol. 105, no. 11, pp. 1641-1649, 2000.

[66] Z. X. Jin, Q. Xiong, F. Jia, C. L. Sun, H. T. Zhu, and F. S. Ke, "Investigation of rna interference suppression of matrix metalloproteinase-9 in mouse model of atherosclerosis," International Journal of Clinical and Experimental Medicine, vol. 8, no. 4, pp. 5272-5278, 2015.

[67] Z. S. Galis, C. Johnson, D. Godin et al., "Targeted disruption of the matrix metalloproteinase-9 gene impairs smooth muscle cell migration and geometrical arterial remodeling," Circulation Research, vol. 91, no. 9, pp. 852-859, 2002.

[68] C. Tan, Y. Liu, W. Li et al., "Associations of matrix metalloproteinase- 9 and monocyte chemoattractant protein1 concentrations with carotid atherosclerosis, based on measurements of plaque and intima-media thickness," Atherosclerosis, vol. 232, no. 1, pp. 199-203, 2014.

[69] F. J. Olson, C. Schmidt, A. Gummesson et al., "Circulating matrix metalloproteinase 9 levels in relation to sampling methods, femoral and carotid atherosclerosis," Journal of Internal Medicine, vol. 263, no. 6, pp. 626-635, 2008.

[70] K. Jung, M. Lein, C. Laube, and R. Lichtinghagen, "Blood specimen collection methods influence the concentration and the diagnostic validity of matrix metalloproteinase 9 in blood," Clinica chimica acta; international journal of clinical chemistry, vol. 314, no. 1-2, pp. 241-244, 2001.

[71] N. Kobayashi, N. Hata, N. Kume et al., "Matrix metalloproteinase- 9 for the earliest stage acute coronary syndrome," Circulation Journal, vol. 75, no. 12, pp. 2853-2861, 2011.

[72] Y. Ino, T. Kubo, A. Tanaka et al., "Difference of culprit lesion morphologies between st-segment elevation myocardial infarction and non-st-segment elevation acute coronary syndrome: an optical coherence tomography study," JACC. Cardiovascular interventions, vol. 4, no. 1, pp. 76-82, 2011.

[73] D. N. Tziakas, M. K. Lazarides, I. K. Tentes et al., "Gelatinases [matrix metalloproteinase-2 (mmp-2) and mmp-9] induce carotid plaque instability but their systemic levels are not pre- dictive of local events," Annals of Vascular Surgery, vol. 19, no. 4, pp. 529-533, 2005.

[74] A. Bar-Or, R. K. Nuttall, M. Duddy et al., "Analyses of all matrix metalloproteinase members in leukocytes emphasize monocytes as major inflammatory mediators in multiple sclerosis," Brain, vol. 126, no. 12, pp. 2738-2749, 2003.

[75] S. H. Kim, Y. J. Kang, W. J. Kim et al., “Tweak can induce proinflammatory cytokines and matrix metalloproteinase- 9 in macrophages," Circulation Journal, vol. 68, no. 4, pp. 396399, 2004.

[76] J. A. Ardans, A. P. Economou, J. M. Martinson Jr., M. Zhou, and L. M. Wahl, "Oxidized low-density and high-density lipoproteins regulate the production of matrix metalloproteinase- 1 and -9 by activated monocytes," Journal of Leukocyte Biology, vol. 71, no. 6, pp. 1012-1018, 2002.

[77] S. Brunner, J. O. Kim, and H. Methe, "Relation of matrix metalloproteinase-9/tissue inhibitor of metalloproteinase-1 ratio in peripheral circulating cd14+ monocytes to progression of coronary artery disease," The American Journal of Cardiology, vol. 105, no. 4, pp. 429-434, 2010.

[78] L. M. Bradley, M. F. Douglass, D. Chatterjee, S. Akira, and B. J. G. Baaten, "Matrix metalloprotease 9 mediates neutrophil migration into the airways in response to influenza virus-induced toll-like receptor signaling," PLoS pathogens, vol. 8, no. $4,2012$.

[79] O. Soehnlein, "Multiple roles for neutrophils in atherosclerosis," Circulation Research, vol. 110, no. 6, pp. 875-888, 2012.

[80] G. Opdenakker, P. E. Van den Steen, B. Dubois et al., "Gelatinase b functions as regulator and effector in leukocyte biology," Journal of Leukocyte Biology, vol. 69, no. 6, pp. 851859, 2001.

[81] T. Koizumi, N. Komiyama, and S. Nishimura, "In-vivo higher plasma levels of platelet-derived growth factor and matrix metalloproteinase- 9 in coronary artery at the very onset of myocardial infarction with st-segment elevation," Annals of Vascular Diseases, vol. 8, no. 4, pp. 297-301, 2015.

[82] J. J. Kaden, C. E. Dempfle, T. Sueselbeck et al., "Time-dependent changes in the plasma concentration of matrix metalloproteinase 9 after acute myocardial infarction," Cardiology, vol. 99, no. 3, pp. 140-144, 2003.

[83] H. Funayama, S. E. Ishikawa, N. Kubo et al., "Increases in interleukin-6 and matrix metalloproteinase- 9 in the infarctrelated coronary artery of acute myocardial infarction," Circulation Journal, vol. 68, no. 5, pp. 451-454, 2004.

[84] Y. Inokubo, H. Hanada, H. Ishizaka, T. Fukushi, T. Kamada, and K. Okumura, "Plasma levels of matrix metalloproteinase9 and tissue inhibitor of metalloproteinase- 1 are increased in the coronary circulation in patients with acute coronary syndrome," American Heart Journal, vol. 141, no. 2, pp. 211-217, 2001.

[85] S. Higo, M. Uematsu, M. Yamagishi et al., "Elevation of plasma matrix metalloproteinase- 9 in the culprit coronary artery in patients with acute myocardial infarction: clinical evidence from distal protection," Circulation Journal, vol. 69, no. 10, pp. 1180-1185, 2005.

[86] G. M. Hamed and M. F. Fattah, "Clinical relevance of matrix metalloproteinase 9 in patients with acute coronary syndrome," Clinical and Applied Thrombosis/Hemostasis, vol. 21, no. 8, pp. 705-711, 2014.

[87] N. Eldrup, M. L. M. Grønholdt, H. Sillesen, and B. G. Nordestgaard, "Elevated matrix metalloproteinase- 9 associated 
with stroke or cardiovascular death in patients with carotid stenosis," Circulation, vol. 114, no. 17, pp. 1847-1854, 2006.

[88] B. J. Jefferis, P. Whincup, P. Welsh et al., "Prospective study of matrix metalloproteinase- 9 and risk of myocardial infarction and stroke in older men and women," Atherosclerosis, vol. 208, no. 2, pp. 557-563, 2010.

[89] P. Garvin, L. Jonasson, L. Nilsson, M. Falk, and M. Kristenson, "Plasma matrix metalloproteinase-9 levels predict first-time coronary heart disease: an 8-year followup of a community-based middle aged population," PLoS One, vol. 10, no. 9, 2015.

[90] P. Welsh, P. H. Whincup, O. Papacosta et al., "Serum matrix metalloproteinase- 9 and coronary heart disease: a prospective study in middle-aged men," QJM, vol. 101, no. 10, pp. 785-791, 2008.

[91] N. Eldrup, C. Kragelund, R. Steffensen, and B. G. Nordestgaard, "Prognosis by c-reactive protein and matrix metalloproteinase- 9 levels in stable coronary heart disease during 15 years of follow-up," Nutrition, Metabolism, and Cardiovascular Diseases, vol. 22, no. 8, pp. 677-683, 2012.

[92] S. Blankenberg, H. J. Rupprecht, O. Poirier et al., "Plasma concentrations and genetic variation of matrix metalloproteinase 9 and prognosis of patients with cardiovascular disease," Circulation, vol. 107, no. 12, pp. 1579-1585, 2003.

[93] T. J. O'Farrell and T. Pourmotabbed, "Identification of structural elements important for matrix metalloproteinase type $\mathrm{v}$ collagenolytic activity as revealed by chimeric enzymes. Role of fibronectin-like domain and active site of gelatinase b," The Journal of Biological Chemistry, vol. 275, no. 36, pp. 2796427972, 2000.

[94] J. A. Allan, A. J. P. Docherty, P. J. Barker, N. S. Huskisson, J. J. Reynolds, and G. Murphy, "Binding of gelatinases a and b to type-i collagen and other matrix components," The Biochemical Journal, vol. 309, no. 1, pp. 299-306, 1995.

[95] B. Zhang, S. Ye, S. M. Herrmann et al., "Functional polymorphism in the regulatory region of gelatinase b gene in relation to severity of coronary atherosclerosis," Circulation, vol. 99, no. 14, pp. 1788-1794, 1999.

[96] G. Wu, H. Cai, G. Li et al., "Influence of the matrix metalloproteinase 9 geners3918242 polymorphism on development of ischemic stroke: a meta-analysis," World Neurosurgery, vol. 133, pp. e31-e61, 2020.

[97] P. J. Pollanen, P. J. Karhunen, J. Mikkelsson et al., "Coronary artery complicated lesion area is related to functional polymorphism of matrix metalloproteinase 9 gene: an autopsy study," Arteriosclerosis, Thrombosis, and Vascular Biology, vol. 21, no. 9, pp. 1446-1450, 2001.

[98] A. R. Morgan, B. Zhang, W. Tapper, A. Collins, and S. Ye, "Haplotypic analysis of the mmp-9 gene in relation to coronary artery disease," Journal of Molecular Medicine (Berlin, Germany), vol. 81, no. 5, pp. 321-326, 2003.

[99] M. Saedi, A. Vaisi-Raygani, S. Khaghani et al., "Matrix metalloproteinas-9 functional promoter polymorphism $1562 c>t$ increased risk of early-onset coronary artery disease," Molecular Biology Reports, vol. 39, no. 1, pp. 555-562, 2012.

[100] L. Wang, Y. T. Ma, X. Xie et al., "Interaction between mmp-9 gene polymorphisms and smoking in relation to myocardial infarction in a uighur population," Clinical and Applied Thrombosis/Hemostasis, vol. 18, no. 1, pp. 72-78, 2012.

[101] L. Wang, Y. T. Ma, X. Xie et al., "Association of mmp-9 gene polymorphisms with acute coronary syndrome in the uygur population of China," World Journal of Emergency Medicine, vol. 2, no. 2, pp. 104-110, 2011.

[102] H. D. Wu, X. Bai, D. M. Chen, H. Y. Cao, and L. Qin, “Association of genetic polymorphisms in matrix metalloproteinase- 9 and coronary artery disease in the chinese han population: a case-control study," Genetic Testing and Molecular Biomarkers, vol. 17, no. 9, pp. 707-712, 2013.

[103] J. S. Kim, H. Y. Park, J. H. Kwon et al., "The roles of stromelysin1 and the gelatinase b gene polymorphism in stable angina," Yonsei Medical Journal, vol. 43, no. 4, pp. 473-481, 2002.

[104] E. Alp, S. Menevse, M. Tulmac et al., "Lack of association between matrix metalloproteinase- 9 and endothelial nitric oxide synthase gene polymorphisms and coronary artery disease in turkish population," DNA and Cell Biology, vol. 28, no. 7, pp. 343-350, 2009.

[105] J. Wang, D. Warzecha, D. Wilcken, and X. L. Wang, "Polymorphism in the gelatinase b gene and the severity of coronary arterial stenosis," Clinical Science, vol. 101, no. 1, pp. 87-92, 2001.

[106] T. B. Opstad, A. A. R. Pettersen, T. W. Weiss et al., "Genetic variation, gene-expression and circulating levels of matrix metalloproteinase- 9 in patients with stable coronary artery disease," Clinica chimica acta; international journal of clinical chemistry, vol. 413, no. 1-2, pp. 113-120, 2012.

[107] D. Nuzzo, S. Vasto, C. R. Balistreri et al., "Role of proinflammatory alleles in longevity and atherosclerosis: results of studies performed on $-1562 \mathrm{c} / \mathrm{t} \mathrm{mmp}-9$ in centenarians and myocardial infarction patients from sicily," Annals of the New York Academy of Sciences, vol. 1089, pp. 496-501, 2006.

[108] F. X. Zhang, D. P. Sun, N. Guan, J. J. Chen, X. C. Huo, and J. S. Luo, “Association between $-1562 \mathrm{c}>\mathrm{t}$ polymorphism in the promoter region of matrix metalloproteinase- 9 and coronary artery disease: a meta-analysis," Genetic Testing and Molecular Biomarkers, vol. 18, no. 2, pp. 98-105, 2014.

[109] J. Wang, D. Xu, X. Wu et al., "Polymorphisms of matrix metalloproteinases in myocardial infarction: a meta-analysis," Heart, vol. 97, no. 19, pp. 1542-1546, 2011.

[110] Z. Juan, Z. Wei-Guo, S. Heng-Liang, and W. da-Guo, "Association of matrix metalloproteinase $9 \mathrm{c}-1562 \mathrm{t}$ polymorphism with genetic susceptibility to myocardial infarction: a metaanalysis," Current Therapeutic Research, Clinical and Experimental, vol. 77, pp. 40-45, 2015.

[111] G. Murphy, "Tissue inhibitors of metalloproteinases," Genome Biology, vol. 12, no. 11, p. 233, 2011.

[112] M. R. de Vries, H. W. M. Niessen, C. W. G. M. Löwik, J. F. Hamming, J. W. Jukema, and P. H. A. Quax, "Plaque rupture complications in murine atherosclerotic vein grafts can be prevented by timp-1 overexpression," PLoS One, vol. 7, no. 10, 2012.

[113] B. R. Dodd and R. A. Spence, "Doxycycline inhibition of abdominal aortic aneurysm growth: a systematic review of the literature," Current Vascular Pharmacology, vol. 9, no. 4, pp. 471-478, 2011.

[114] J. Golledge and P. E. Norman, "Current status of medical management for abdominal aortic aneurysm," Atherosclerosis, vol. 217, no. 1, pp. 57-63, 2011.

[115] F. Zhang, L. Hu, Y. X. Wu et al., "Doxycycline alleviates paraquat-induced acute lung injury by inhibiting neutrophilderived matrix metalloproteinase 9," International Immunopharmacology, vol. 72, pp. 243-251, 2019.

[116] E. P. Samartzis, D. Fink, M. Stucki, and P. Imesch, "Doxycycline reduces mmp-2 activity and inhibits invasion of $12 \mathrm{z}$ 
epithelial endometriotic cells as well as mmp-2 and -9 activity in primary endometriotic stromal cells in vitro," Reproductive Biology and Endocrinology, vol. 17, no. 1, p. 38, 2019.

[117] M. Pawlowska, M. Gajda, G. Pyka-Fosciak et al., "The effect of doxycycline on atherogenesis in apoe-knockout mice," Journal of Physiology and Pharmacology, vol. 62, no. 2, pp. 247-250, 2011.

[118] V. Mannacio, L. di Tommaso, A. Antignano, E. di Tommaso, P. Stassano, and C. Vosa, "Doxycycline prevents intimal hyperplasia in vitro and may improve patency of the internal thoracic artery," BioMed research international, vol. 2013, 6 pages, 2013.

[119] B. Axisa, I. M. Loftus, A. R. Naylor et al., "Prospective, randomized, double-blind trial investigating the effect of doxycycline on matrix metalloproteinase expression within atherosclerotic carotid plaques," Stroke, vol. 33, no. 12, pp. 2858-2864, 2002.

[120] D. L. Brown, K. K. Desai, B. A. Vakili, C. Nouneh, H. M. Lee, and L. M. Golub, "Clinical and biochemical results of the metalloproteinase inhibition with subantimicrobial doses of doxycycline to prevent acute coronary syndromes (midas) pilot trial," Arteriosclerosis, Thrombosis, and Vascular Biology, vol. 24, no. 4, pp. 733-738, 2004.

[121] S. Takai, D. Jin, S. Inagaki, D. Yamamoto, K. Tanaka, and M. Miyazaki, "Significance of matrix metalloproteinase-9 in cardiac dysfunction during the very acute phase after myocardial infarction in hamsters," European Journal of Pharmacology, vol. 572, no. 1, pp. 57-60, 2007.

[122] R. Mukherjee, T. A. Brinsa, K. B. Dowdy et al., "Myocardial infarct expansion and matrix metalloproteinase inhibition," Circulation, vol. 107, no. 4, pp. 618-625, 2003.

[123] M. P. Hudson, P. W. Armstrong, W. Ruzyllo et al., "Effects of selective matrix metalloproteinase inhibitor (pg-116800) to prevent ventricular remodeling after myocardial infarction," Journal of the American College of Cardiology, vol. 48, no. 1, pp. 15-20, 2006.

[124] J. L. Johnson, R. Fritschedanielson, M. Behrendt et al., "Effect of broad-spectrum matrix metalloproteinase inhibition on atherosclerotic plaque stability," Cardiovascular Research, vol. 71, no. 3, pp. 586-595, 2006.

[125] K. K. Koh, "Effects of statins on vascular wall: vasomotor function, inflammation, and plaque stability," Cardiovascular Research, vol. 47, no. 4, pp. 648-657, 2000.

[126] L. H. Opie, "Present status of statin therapy," Trends in cardiovascular medicine, vol. 25, no. 3, pp. 216-225, 2015.

[127] A. Blum, "Hmg-coa reductase inhibitors (statins), inflammation, and endothelial progenitor cells-new mechanistic insights of atherosclerosis," BioFactors, vol. 40, no. 3, pp. 295-302, 2014.

[128] Z. Luan, A. J. Chase, and A. C. Newby, "Statins inhibit secretion of metalloproteinases-1, -2, -3, and -9 from vascular smooth muscle cells and macrophages," Arteriosclerosis, Thrombosis, and Vascular Biology, vol. 23, no. 5, pp. 769-775, 2003.

[129] Y. Rival, N. Benéteau, V. Chapuis et al., "Cardiovascular drugs inhibit mmp-9 activity from human thp-1 macrophages," DNA and Cell Biology, vol. 23, no. 5, pp. 283-292, 2004.

[130] Z. Xu, S. Zhao, H. Zhou, H. Ye, and J. Li, “Atorvastatin lowers plasma matrix metalloproteinase-9 in patients with acute coronary syndrome," Clinical Chemistry, vol. 50, no. 4, pp. 750$753,2004$.

[131] S. Takai, D. Yamamoto, D. Jin et al., "Inhibition of matrix metalloproteinase- 9 activity by lisinopril after myocardial infarction in hamsters," European Journal of Pharmacology, vol. 568, no. 1-3, pp. 231-233, 2007.

[132] D. Yamamoto, S. Takai, D. Jin, S. Inagaki, K. Tanaka, and M. Miyazaki, "Molecular mechanism of imidapril for cardiovascular protection via inhibition of mmp-9," Journal of Molecular and Cellular Cardiology, vol. 43, no. 6, pp. 670-676, 2007.

[133] C. A. Schuyler, N. N. Ta, Y. Li, M. F. Lopes-Virella, and Y. Huang, "Insulin treatment attenuates diabetes-increased atherosclerotic intimal lesions and matrix metalloproteinase 9 expression in apolipoprotein e-deficient mice," The Journal of Endocrinology, vol. 210, no. 1, pp. 37-46, 2011.

[134] N. Marx, J. Froehlich, L. Siam et al., "Antidiabetic PPAR $\gamma$ activator rosiglitazone reduces mmp-9 serum levels in type 2 diabetic patients with coronary artery disease," Arteriosclerosis, Thrombosis, and Vascular Biology, vol. 23, no. 2, pp. 283-288, 2003.

[135] A. Iwakura, S. Shastry, C. Luedemann et al., "Estradiol enhances recovery after myocardial infarction by augmenting incorporation of bone marrow-derived endothelial progenitor cells into sites of ischemia-induced neovascularization via endothelial nitric oxide synthase-mediated activation of matrix metalloproteinase-9," Circulation, vol. 113, no. 12, pp. 1605-1614, 2006.

[136] H. Uzui, S. K. Sinha, and T. B. Rajavashisth, "17beta-estradiol inhibits oxidized low-density lipoprotein-induced increase in matrix metalloproteinase- 9 expression in human macrophages," Journal of Investigative Medicine, vol. 59, no. 7, pp. 1104-1108, 2015.

[137] X. Wang, H. Lv, Y. Gu et al., "Protective effect of lycopene on cardiac function and myocardial fibrosis after acute myocardial infarction in rats via the modulation of p38 and mmp-9," Journal of Molecular Histology, vol. 45, no. 1, pp. 113-120, 2014.

[138] E. Scoditti, N. Calabriso, M. Massaro et al., "Mediterranean diet polyphenols reduce inflammatory angiogenesis through mmp-9 and cox- 2 inhibition in human vascular endothelial cells: a potentially protective mechanism in atherosclerotic vascular disease and cancer," Archives of Biochemistry and Biophysics, vol. 527, no. 2, pp. 81-89, 2012.

[139] G. Liu, B. Wang, J. Zhang, H. Jiang, and F. Liu, “Total panax notoginsenosides prevent atherosclerosis in apolipoprotein eknockout mice: role of downregulation of cd40 and mmp-9 expression," Journal of Ethnopharmacology, vol. 126, no. 2, pp. 350-354, 2009.

[140] Z. Y. Fang, R. Lin, B. X. Yuan, Y. Liu, and H. Zhang, "Tanshinone iia inhibits atherosclerotic plaque formation by downregulating mmp-2 and mmp-9 expression in rabbits fed a highfat diet," Life Sciences, vol. 81, no. 17-18, pp. 1339-1345, 2007.

[141] M. Ezhov, M. Safarova, O. Afanasieva, M. Mitroshkin, Y. Matchin, and S. Pokrovsky, "Matrix metalloproteinase 9 as a predictor of coronary atherosclerotic plaque instability in stable coronary heart disease patients with elevated lipoprotein(a) levels," Biomolecules, vol. 9, no. 4, p. 129, 2019.

[142] L. Chen, Q. Yang, R. Ding, D. Liu, and Z. Chen, "Carotid thickness and atherosclerotic plaque stability, serum inflammation, serum mmp-2 and mmp-9 were associated with acute cerebral infarction," Experimental and Therapeutic Medicine, vol. 16, no. 6, pp. 5253-5257, 2018.

[143] A. Müller, S. D. Krämer, R. Meletta et al., "Gene expression levels of matrix metalloproteinases in human atherosclerotic plaques and evaluation of radiolabeled inhibitors as imaging agents for plaque vulnerability," Nuclear Medicine and Biology, vol. 41, no. 7, pp. 562-569, 2014. 